\title{
The treatment of acute nerve function impairment in leprosy: results from a prospective cohort study in Bangladesh
}

\author{
RICHARD P. CROFT*, PETER G. NICHOLLS**, \\ JAN H. RICHARDUS+ \& W. CAIRNS S. SMITH** \\ *The Danish-Bangladesh Leprosy Mission (DBLM), \\ Nilphamari, Bangladesh \\ **Department of Public Health, University of Aberdeen, \\ Scotland, UK \\ +Department of Public Health, Erasmus University Rotterdam, \\ The Netherlands
}

\section{Accepted for publication 9 March 2000}

\begin{abstract}
Summary In this paper, the outcome of 132 patients having acute nerve function impairment (NFI) is reported at 4 and 12 months after the start of prednisolone treatment. In all, $68 \%$ of sensory nerves and $67 \%$ of motor nerves showed improvement at 12 months, with no statistical difference in responsiveness of various nerves to prednisolone. Duration and severity of impairment were not found significant predictors of treatment outcome. A core of $32 \%$ of impaired nerves did not respond to prednisolone, and $12 \%$ of impaired nerves had functional deterioration despite treatment. The mean eye-hand-foot (EHF) score improved from 2.02 to 1.33 in the treatment group (median score improved from 2 to 1). Approximately one-third of all patients requiring prednisolone treatment did not receive it, an important reason being that some patients developed new NFI against a background of chronic impairment, and were thus overlooked. The 'unjustly untreated' group of patients had a spontaneous sensory nerve function improvement rate of $62 \%$ and a motor nerve function improvement rate of $33 \%$ at 12 months from onset of NFI. The EHF score showed no statistically significant improvement.
\end{abstract}

\section{Introduction}

There is a wide literature reporting the response of nerve function impairment (NFI) and leprosy reactions to treatment with corticosteroids, and the topic has recently been reviewed. ${ }^{1}$ In the past few years, there has been a shift towards the ambulatory treatment of reactions and nerve damage and a movement away from hospital based treatment, ${ }^{2-6}$ and standardized or semi-standardized corticosteroid regimens have been used more widely. ${ }^{2,5,6}$ In addition, 
there has been a movement both towards the recognition of NFI as a primary indication for treatment, and away from the clinically more obvious 'reactions'. ${ }^{5-7}$ There is an increasing recognition that corticosteroids as a form of therapy have limitations, and that other treatment modalities should be explored. ${ }^{1,8}$ However, despite this, corticosteroids remain the mainstay of treatment, and the most recent WHO Expert Committee on leprosy confirmed this by stating that 'most reactions and neuritis can be treated successfully under field conditions with a standard 12-week course of prednisolone'.

Despite the large amount of literature on the treatment of reactions, there are no controlled trials reported on the use of corticosteroids to treat leprosy reactions or NFI. Steroid treatment was introduced at a time when this type of study was unusual, and the drug's value was apparently so clear that it became unethical to consider carrying out such a trial. Most studies that have been carried out are retrospective in nature, and this is a weakness. Variations in the use of terminology also present a problem, making it difficult to compare studies. In addition, different measurement techniques have been used in the studies assessing nerve function, which introduces a further complication.

The Bangladesh Acute Nerve Damage Study (BANDS) is a prospective cohort study designed to investigate the epidemiology of nerve function impairment (NFI) in leprosy patients, its risk factors and response to treatment. ${ }^{10}$ BANDS is based at a single centre in Bangladesh, the Danish Bangladesh Leprosy Mission (DBLM). This paper describes the response to treatment by corticosteroids of cohort patients who developed acute NFI.

The treatment of NFI and leprosy reactions at DBLM is largely field-based. This policy follows a successful pilot study carried out in 1994 in part of the DBLM project area to investigate the feasibility and effectiveness of such a system. ${ }^{5}$

The present study is prospective in nature and uses standard measures of nerve function that are common to all the studies being carried out in BANDS giving both continuity and consistency to the results.

\section{Materials and methods}

\section{STUDY GROUP}

The study group was the BANDS cohort. The 2664 patients, recruited over a 12-month period, comprised 1481 males (56\%) and 1183 females (44\%). Of these, $2220(83 \%)$ of the patients were paucibacillary (PB), and 444 (17\%) were multibacillary (MB).

Patients developing NFI either by registration time or during the first 12 months of follow-up were assessed initially in the field by trained leprosy control assistants, supervisors and physiotechnicians. ${ }^{10}$ The patients were then either given treatment by staff in the field using corticosteroids in standard doses, or referred to hospital where necessary.

DEFINITIONS OF NFI

NFI was defined as follows:

Sensory NFI: reduction by $\geq 2$ points in the sensory distribution of any one nerve, as tested by ballpoint pen. The following nerves were tested for sensory function: ulnar (five sites), median (seven sites), posterior tibial (11 sites). The positions of the test sites were shown in an earlier paper. ${ }^{10}$ 
Motor NFI: reduction by $\geq 2$ in the MRC grade of the movement tested of any one nerve. Nerves tested for motor function were: facial, ulnar, median, radial, lateral popliteal. ${ }^{10}$

TREATMENT

The standard prednisolone regimen used in the field for the treatment of NFI amongst adults was as follows: $40 \mathrm{mg}$, 4 weeks; $30 \mathrm{mg}, 2$ weeks; $25 \mathrm{mg}$, 2 weeks; $20 \mathrm{mg}$, 2 weeks; $15 \mathrm{mg}, 2$ weeks; $10 \mathrm{mg}, 2$ weeks; $5 \mathrm{mg}, 2$ weeks. The total length of treatment was 16 weeks. The dosages were reduced for patients with body weight $<35 \mathrm{~kg}$. Patients were referred to hospital if they had motor paralysis requiring intensive physiotherapy, or if they had concomitant complications or conditions such as neuropathic ulcers, anaemia, intercurrent infection or pregnancy. In addition, patients failing to respond to prednisolone were referred to hospital. In hospital, prednisolone was usually continued in the dosages mentioned above, but occasionally doses as high as $80 \mathrm{mg} /$ day were used, treatment being titrated against response

Patients developing leprosy reactions in the absence of NFI were also treated with prednisolone, and sometimes other agents including aspirin and clofazimine were prescribed in accordance with the project treatment guidelines. However, only patients with NFI are considered in this study.

Patients were followed up in the field and in hospital, and their nerve function scores were recorded. From this, records at 4 and 12 months after starting prednisolone therapy were analysed, and the findings are reported in this paper.

\section{OUTCOMES}

Outcome was expressed in two broad ways. Firstly, the result of treatment of sensory and motor functions for individual nerves was given at 4 and 12 months, using the following definitions:

- Full recovery: restoration of sensory or motor score to normal.

- Partial recovery: improvement in sensory or motor score by $\geq 2$ points, but less than full return to normal.

- Same: no change in sensory/motor score, or change by only 1 point.

- Deterioration (worse): deterioration in sensory or motor score by $\geq 2$ points.

Outcomes were expressed as simple proportions, using Epi Info software to determine the Fleiss quadratic $95 \%$ confidence intervals (CIs). In addition, a dichotomous definition of outcome was used: 'Improvement' included 'full' and 'partial' recovery of function, and 'Same or Worse' included 'same' and 'deterioration'.

Nerves were divided into two groups depending on whether the nerve was 'severely' affected or not. For motor function, MRC grades 0 or 1 (i.e. paralysis) were taken as severe, and grades 2 and 3 as mild. For sensory function, a reduction in $3+$ points in the ulnar (maximum 5 points) or median (maximum 7 points) nerve distribution, or $5+$ points in the posterior tibial (maximum 11 points) nerve distribution was taken as severe. Mild sensory loss was a 2-point reduction for the ulnar and median nerves, and a 2- to 4-point reduction for the posterior tibial nerve.

Patients were divided into two groups, $0-1$ month duration of nerve damage and 2-6 months duration, based on a report that patients with $<1$ month duration of nerve damage recover better than those with longer duration of damage. ${ }^{6}$ 
Secondly, average EHF scores were calculated. The WHO disability grading system applies a score of 0,1 or 2 to each limb and eye, and the overall disability grade is usually determined by the part of the body with most damage. ${ }^{11}$ However, the individual body part scores could be added to give a sum 'EHF' score that expressed the level of impairment with more accuracy. ${ }^{12-14}$ In this system, a score of 0 indicates no impairment, and the maximum score of 12 indicates visible deformity of both hands and feet combined with, for example, bilateral lagophthalmos and blindness. Mean EHF scores were calculated at registration, 4 and 12 months, and Student's $t$-test used to find the CIs for differences between means. In the calculation of the disability grade for eyes, the most recent WHO definition was used which assigns all lagophthalmos to grade $2 .^{9}$

\section{TREATED AND UNTREATED PATIENTS}

In addition to the group of patients treated for NFI, another group was identified that according to the criteria should have received prednisolone treatment but for various reasons did not do so. The development of NFI in these 'unjustly untreated' patients has been analysed in a similar way to the treated group. The 'unjustly untreated' patients cannot be considered a true control group because of a lack of randomization. Nevertheless, because of the considerable importance of these patients, the outcomes of both groups are compared and discussed.

\section{Results}

OVERVIEW OF PATIENT GROUP

A total of 214 patients were identified who developed NFI within the first 12 months of follow-up. Of these, 90 had NFI present at registration, and 124 developed NFI requiring prednisolone treatment during the first year after registration. Thirty-seven patients out of 214 required hospital admission for treatment, the remainder being treated 'in the field'. At 4 months after the start of prednisolone treatment, 186 records were available for analysis, but by 12 months, follow-up records were complete for 201 (i.e. 15 patients did not attend clinic at 4 months, but did so by 12 months). Of the 13 patients lost to follow-up at 12 months (6\% of the total), there were: 11 males and two females; eight MB and five PB; 13 adults; six received prednisolone and seven did not.

A group of patients was identified who should have received prednisolone for NFI but did not do so. In all, 132/201 (66\%) patients received prednisolone, and 69/201 (34\%) did not. Table 1 compares the two groups for sex, leprosy group, age, severity of NFI (see definition at foot of table) and duration of NFI (0-1 months and 2-6 months) with $\chi^{2}$ and $P$-values given. For sex, leprosy group and age the treated and untreated groups do not differ materially, $P$-values being $>0.3$ for each $\chi^{2}$ test. However, the groups differed significantly in the proportions of patients with short/long duration and mild/severe NFI, with a $P$-value of $<0.05$ for both variables in the $\chi^{2}$ test. There is a significantly higher proportion of patients with short duration NFI and severe NFI in the untreated group.

OUTCOMES AT 4 AND 12 MONTHS

Table 2 shows outcomes at 4 and 12 months, respectively, for the eight nerve function modalities (facial motor, ulnar sensory and motor, median sensory and motor, radial motor, 
Table 1. Comparison between treated and untreated patient groups

\begin{tabular}{|c|c|c|c|c|c|c|}
\hline Category & Factor & Treated group & Untreated group & Total & $\chi^{2}$ & $P$-value \\
\hline Sex & $\begin{array}{l}\text { Male } \\
\text { Female }\end{array}$ & $\begin{array}{l}95(72) \\
37(28)\end{array}$ & $\begin{array}{l}47(68) \\
22(32)\end{array}$ & $\begin{array}{r}142(71) \\
59(29)\end{array}$ & $0 \cdot 32$ & $0 \cdot 57$ \\
\hline Leprosy group & $\begin{array}{l}\mathrm{MB} \\
\mathrm{PB}\end{array}$ & $\begin{array}{l}74(56) \\
58(44)\end{array}$ & $\begin{array}{l}39(56) \\
30(44)\end{array}$ & $\begin{array}{r}113(56) \\
88(44)\end{array}$ & 0.00 & 0.95 \\
\hline Age group & $\begin{array}{l}\text { Adult }(15+) \\
\text { Child }(<15)\end{array}$ & $\begin{array}{r}124(94) \\
8 \quad(6)\end{array}$ & $\begin{aligned} 67 & (97) \\
2 & (3)\end{aligned}$ & $\begin{array}{c}191(95) \\
10(5)\end{array}$ & 0.96 & $0 \cdot 33$ \\
\hline Duration of NFI & $\begin{array}{l}0-1 \text { months } \\
2-6 \text { months }\end{array}$ & $\begin{array}{l}83(63) \\
49(37)\end{array}$ & $\begin{array}{l}55(80) \\
14(20)\end{array}$ & $\begin{array}{r}138(69) \\
63(31)\end{array}$ & 5.97 & 0.015 \\
\hline Severity of NFI* & $\begin{array}{l}\text { Mild } \\
\text { Severe }\end{array}$ & $\begin{array}{l}47(36) \\
85(64)\end{array}$ & $\begin{array}{l}14(20) \\
55(80)\end{array}$ & $\begin{array}{r}61(30) \\
140(70)\end{array}$ & 5.03 & 0.025 \\
\hline Total & All & $132(66)$ & $69(34)$ & 201 & & \\
\hline
\end{tabular}

* Severe NFI = presence of any of the following: MRC grades 0,1 for any motor nerve tested; or 3+ sensory point reduction for ulnar/median nerve distribution; or 5+ sensory point reduction for posterior tibial nerve distribution.

Mild NFI = patient with no nerve having severe NFI as defined above.

Figures in brackets are percentages.

lateral popliteal motor and posterior tibial sensory) using the outcomes of full recovery, partial recovery, same and worse. $95 \%$ CIs have not been given for the outcome of the function of individual nerves, since the numbers are small and the resultant CIs have wide limits.

There was a higher proportion of nerves with full recovery amongst the treated group than the untreated group. At 12 months, 33\% (23-44) of the treated motor nerves had recovered fully compared with $8 \%(2-24)$ of the untreated ones; $37 \%(30-45)$ of the treated sensory nerves had recovered fully compared with $17 \%(10-29)$ of the untreated ones. Proportions with full recovery amongst the individual nerve function modalities show higher levels of full recovery for the facial nerve (53\% at 4 months, $58 \%$ at 12 months) and the median sensory modality (59\% at 4 months and $62 \%$ at 12 months). However, numbers are small.

Amongst individual nerve modalities there was a fairly uniform level of improvement, but the facial nerve ( $82 \%$ at 12 months) and ulnar sensory modality ( $84 \%$ at 12 months) recovered slightly better than the other nerves, and the lateral popliteal responded least well (47\% at 12 months).

Using the broader 'improvement' and 'same or worse' categories, amongst nerves with motor NFI, 74\% (63-83) showed improvement at 4 months, sustained amongst $67 \%$ (56-77) at 12 months. This compares with 20\% (8-39) improving without treatment at 4 months, rising to $33 \%(19-51)$ at 12 months. For sensory function, the overall proportion improving at 4 months was $73 \%$ (65-80), falling to $68 \%(60-75)$ at 12 months. Forty-five percent (33-58) of the untreated group showed sensory improvement at 4 months and $62 \%$ (50-73) at 12 months after being diagnosed with acute NFI.

A substantial proportion of patients did not benefit from prednisolone treatment. Overall, $32 \%(25-40)$ of nerves with sensory impairment and 38\% (27-50) of nerves with motor impairment either had the same level of function at 12 months, or they had deteriorated. Thirteen percent (9-20) of nerves with sensory NFI and 12\% (5-22) of motor function of nerves had actually deteriorated despite treatment. 
Table 2. Outcome of treatment of NFI at 4 (A) and 12 (B) months shown by nerve

A

\begin{tabular}{|c|c|c|c|c|c|c|c|c|c|c|c|c|c|c|}
\hline \multirow[b]{2}{*}{ Nerve } & \multirow[b]{2}{*}{$\begin{array}{l}\text { Treatment } \\
\text { status }\end{array}$} & \multicolumn{5}{|c|}{ Outcome at 4 months } & \multicolumn{8}{|c|}{ Outcome at 4 months - proportions } \\
\hline & & $\begin{array}{c}\text { Full } \\
\text { recovery }\end{array}$ & $\begin{array}{l}\text { Partial } \\
\text { recovery }\end{array}$ & Same & Worse & Total & $\begin{array}{c}\text { Full } \\
\text { recovery }\end{array}$ & $95 \% C I$ & $\begin{array}{l}\text { Partial } \\
\text { recovery }\end{array}$ & $95 \% C I$ & Same & $95 \% C I$ & Worse & $95 \% C I$ \\
\hline Facial (M) & Treated & 10 & 6 & 2 & 1 & 19 & 0.53 & & $0 \cdot 32$ & & $0 \cdot 11$ & & 0.05 & \\
\hline Ulnar (M) & Treated & 7 & 19 & 9 & 2 & 37 & $0 \cdot 19$ & & 0.51 & & $0 \cdot 24$ & & 0.05 & \\
\hline Median (M) & Treated & 4 & 3 & 1 & 1 & 9 & 0.44 & & $0 \cdot 33$ & & $0 \cdot 11$ & & $0 \cdot 11$ & \\
\hline $\begin{array}{l}\text { Lateral popliteal } \\
\text { (M) }\end{array}$ & Treated & 3 & 8 & 5 & 0 & 16 & $0 \cdot 19$ & & $0 \cdot 50$ & & $0 \cdot 31$ & & 0.00 & \\
\hline Radial (M) & Treated & 0 & 1 & 0 & 0 & 1 & 0.00 & & 1.00 & & $0 \cdot 00$ & & 0.00 & \\
\hline Ulnar (S) & Treated & 12 & 12 & 5 & 1 & 30 & $0 \cdot 40$ & & $0 \cdot 40$ & & $0 \cdot 17$ & & 0.03 & \\
\hline Median (S) & Treated & 19 & 5 & 5 & 3 & 32 & 0.59 & & $0 \cdot 16$ & & $0 \cdot 16$ & & 0.09 & \\
\hline Posterior tibial (S) & Treated & 26 & 42 & 21 & 8 & 97 & 0.27 & & 0.43 & & $0 \cdot 22$ & & 0.08 & \\
\hline \multirow[t]{2}{*}{ All sensory nerves } & Treated & 57 & 59 & 31 & 12 & 159 & 0.36 & $0.29-0.44$ & $0 \cdot 37$ & $0 \cdot 30-0.45$ & $0 \cdot 19$ & $0.14-0.27$ & 0.08 & $0.04-0.13$ \\
\hline & Untreated & 5 & 23 & 27 & 7 & 62 & 0.08 & $0.03-0.19$ & $0 \cdot 37$ & $0 \cdot 25-0.50$ & 0.44 & $0.31-0.57$ & $0 \cdot 11$ & $0.05-0.22$ \\
\hline \multirow[t]{2}{*}{ All motor nerves } & Treated & 24 & 37 & 17 & 4 & 82 & $0 \cdot 29$ & $0 \cdot 20-0.41$ & $0 \cdot 45$ & $0.34-0.56$ & $0 \cdot 21$ & $0 \cdot 13-0 \cdot 31$ & 0.05 & $0.02-0.13$ \\
\hline & Untreated & 4 & 2 & 22 & 2 & 30 & $0 \cdot 13$ & $0.04-0.32$ & 0.07 & $0.02-0.31$ & 0.73 & $0.54-0.87$ & 0.07 & $0.04-0.32$ \\
\hline
\end{tabular}




\begin{tabular}{|c|c|c|c|c|c|c|c|c|c|c|c|c|c|c|}
\hline \multirow[b]{2}{*}{ Nerve } & \multirow[b]{2}{*}{$\begin{array}{l}\text { Treatment } \\
\text { status }\end{array}$} & \multicolumn{5}{|c|}{ Outcome at 12 months } & \multicolumn{8}{|c|}{ Outcome at 12 months - proportions } \\
\hline & & $\begin{array}{l}\text { Full } \\
\text { recovery }\end{array}$ & $\begin{array}{l}\text { Partial } \\
\text { recovery }\end{array}$ & Same & Worse & Total & $\begin{array}{l}\text { Full } \\
\text { recovery }\end{array}$ & $95 \% C I$ & $\begin{array}{l}\text { Partial } \\
\text { recovery }\end{array}$ & $95 \% C I$ & Same & $95 \% C I$ & Worse & $95 \% C I$ \\
\hline Facial (M) & Treated & 11 & 5 & 1 & 2 & 19 & 0.58 & & $0 \cdot 26$ & & 0.05 & & $0 \cdot 11$ & \\
\hline Ulnar (M) & Treated & 8 & 17 & 8 & 4 & 37 & $0 \cdot 22$ & & 0.46 & & $0 \cdot 22$ & & $0 \cdot 11$ & \\
\hline Median (M) & Treated & 4 & 3 & 3 & 0 & 10 & $0 \cdot 40$ & & $0 \cdot 30$ & & $0 \cdot 30$ & & 0.00 & \\
\hline $\begin{array}{l}\text { Lateral popliteal } \\
\text { (M) }\end{array}$ & Treated & 4 & 4 & 6 & 3 & 17 & $0 \cdot 19$ & & $0 \cdot 25$ & & $0 \cdot 38$ & & $0 \cdot 19$ & \\
\hline Radial (M) & Treated & 1 & 0 & 0 & 0 & 1 & 1.00 & & $0 \cdot 00$ & & $0 \cdot 00$ & & $0 \cdot 00$ & \\
\hline Ulnar (S) & Treated & 14 & 10 & 5 & 2 & 31 & $0 \cdot 45$ & & $0 \cdot 32$ & & $0 \cdot 16$ & & $0 \cdot 06$ & \\
\hline Median (S) & Treated & 21 & 3 & 6 & 4 & 34 & 0.62 & & 0.09 & & $0 \cdot 18$ & & $0 \cdot 12$ & \\
\hline Posterior tibial (S) & Treated & 27 & 38 & 20 & 16 & 101 & $0 \cdot 27$ & & $0 \cdot 38$ & & $0 \cdot 20$ & & $0 \cdot 16$ & \\
\hline \multirow[t]{2}{*}{ All sensory nerves } & Treated & 62 & 51 & 31 & 22 & 166 & 0.37 & $0.30-0.45$ & $0 \cdot 31$ & $0 \cdot 24-0.38$ & $0 \cdot 19$ & $0 \cdot 13-0.26$ & $0 \cdot 13$ & $0.09-0.20$ \\
\hline & Untreated & 12 & 31 & 18 & 8 & 69 & $0 \cdot 17$ & $0 \cdot 10-0.29$ & 0.45 & $0.33-0.67$ & $0 \cdot 26$ & $0 \cdot 17-0.38$ & $0 \cdot 12$ & $0.05-0.22$ \\
\hline \multirow[t]{2}{*}{ All motor nerves } & Treated & 27 & 29 & 18 & 9 & 83 & $0 \cdot 33$ & $0 \cdot 23-0.44$ & 0.35 & $0.25-0.46$ & $0 \cdot 22$ & $0 \cdot 14-0.32$ & $0 \cdot 11$ & $0.05-0.20$ \\
\hline & Untreated & 3 & 9 & 21 & 3 & 36 & $0 \cdot 08$ & $0 \cdot 02-0 \cdot 24$ & 0.25 & $0.13-0.43$ & $0 \cdot 58$ & $0.41-0.74$ & $0 \cdot 08$ & $0.02-0.24$ \\
\hline
\end{tabular}


OUTCOMES FOR SEVERITY OF IMPAIRMENT

Table 3 shows outcomes of treatment for severity of symptoms. At 12 months, 48\% (32-64) of mildly affected sensory nerves recovered fully compared with $34 \%$ (26-43) of severely affected sensory nerves; $41 \%$ (24-59) of mildly affected motor nerves recovered fully compared with $27 \%$ (16-42) of severely affected motor nerves. Overall, 44\% (33-57) of mildly affected nerves recovered fully compared with $32 \%$ (25-40) of severely affected nerves. However, none of these differences is significant at the $5 \%$ level.

There was little difference between the overall outcomes, with 63\% (46-77) of mildly affected sensory nerves showing improvement at 12 months, compared with $70 \%$ (61-78) amongst severely affected sensory nerves. Sixty-nine percent (50-83) of mildly impaired motor nerves showed improvement at 12 months compared with 67\% (52-79) amongst severely affected motor nerves. Overall, 65\% (53-76) of mildly affected nerves (sensory and motor) showed improvement at 12 months compared with 69\% (61-76) of the more severely affected nerves, but this is not a statistically significant difference.

\section{OUTCOMES FOR DIFFERENT DURATIONS OF SYMPTOMS}

Table 4 shows outcomes for duration of symptoms. Once again, there is little difference in outcome between the two groups. A confusing picture is presented, with shorter-duration sensory impaired nerves apparently showing less full recovery than longer-duration impaired nerves at 12 months, i.e. 34\% (24-46) versus 43\% (32-55); but with motor nerves showing the reverse picture, i.e. $39 \%(25-55)$ of shorter-duration impaired nerves fully recovered versus $24 \%(12-42)$ of longer-duration impaired nerves.

The picture with regard to deterioration of function is also confusing, with $20 \%(13-30)$ of the shorter-duration sensory impaired nerves deteriorating in function, but with only $5 \%$ (2-13) of the longer-duration impaired nerves doing so; and with $11 \%$ (4-24) of the shorterduration motor impaired nerves deteriorating in function, and $11 \%(4-26)$ of the longer duration motor impaired nerves.

\section{EHF SCORES}

The starting mean EHF score was higher for the untreated group $(2 \cdot 32 \pm 0 \cdot 22)$ than the treated $(2 \cdot 02 \pm 0.21)$. There was a statistically significant improvement in mean EHF score for the treated group to $1.19 \pm 0.21$ by 4 months, rising slightly to $1.33 \pm 0.27$ by 12 months. There was a gradual, but statistically insignificant, reduction in mean EHF score for the untreated patients to $2.18 \pm 0.22$ by 4 months and $2.13 \pm 0.25$ by 12 months. The median EHF score was 2.00 for both the treated and untreated groups, remaining unchanged in the untreated group at 4 and 12 months, but improving to 1.00 in the treated group at both 4 and 12 months.

\section{Discussion}

OVERALL RECOVERY

The overall levels of recovery amongst the treated patients [overall improvement of $67 \%$ (56-77) amongst motor nerves and 68\% (60-75) amongst sensory nerves at 12 months] are of a very similar order to those found in other studies. A previous study at DBLM found 
Table 3. Outcome of treatment of NFI by severity of NFI symptoms at 4 (A) and 12 (B) months

A

\begin{tabular}{|c|c|c|c|c|c|c|c|c|c|c|c|c|c|c|}
\hline \multirow[b]{2}{*}{$\begin{array}{l}\text { NFI } \\
\text { severity }\end{array}$} & \multirow[b]{2}{*}{$\begin{array}{l}\text { Nerve } \\
\text { modality }\end{array}$} & \multicolumn{5}{|c|}{ Outcome at 4 months } & \multicolumn{8}{|c|}{ Outcome at 4 months } \\
\hline & & Full & Partial & Same & Worse & Total & Full & $95 \% C I$ & Partial & $95 \% C I$ & Same & $95 \% C I$ & Worse & $95 \% C I$ \\
\hline Mild $^{\mathrm{a}}$ & $\begin{array}{l}\text { All sensory } \\
\text { All motor }\end{array}$ & $\begin{array}{r}19 \\
9\end{array}$ & $\begin{array}{l}10 \\
16\end{array}$ & $\begin{array}{l}6 \\
5\end{array}$ & $\begin{array}{l}4 \\
2\end{array}$ & $\begin{array}{l}39 \\
32\end{array}$ & $\begin{array}{l}0.49 \\
0.28\end{array}$ & $\begin{array}{l}0.33-0.65 \\
0.14-0.47\end{array}$ & $\begin{array}{l}0 \cdot 26 \\
0.50\end{array}$ & $\begin{array}{l}0.14-0.42 \\
0.32-0.68\end{array}$ & $\begin{array}{l}0 \cdot 15 \\
0 \cdot 16\end{array}$ & $\begin{array}{l}0 \cdot 06-0 \cdot 31 \\
0.06-0.34\end{array}$ & $\begin{array}{l}0 \cdot 10 \\
0 \cdot 06\end{array}$ & $\begin{array}{l}0.03-0 \cdot 25 \\
0 \cdot 01-0 \cdot 22\end{array}$ \\
\hline Severe ${ }^{\mathrm{b}}$ & $\begin{array}{l}\text { All sensory } \\
\text { All motor }\end{array}$ & $\begin{array}{l}38 \\
15\end{array}$ & $\begin{array}{l}49 \\
21\end{array}$ & $\begin{array}{l}25 \\
12\end{array}$ & $\begin{array}{l}8 \\
2\end{array}$ & $\begin{array}{r}120 \\
50\end{array}$ & $\begin{array}{l}0 \cdot 32 \\
0 \cdot 30\end{array}$ & $\begin{array}{l}0 \cdot 24-0 \cdot 41 \\
0 \cdot 18-0 \cdot 45\end{array}$ & $\begin{array}{l}0.41 \\
0.42\end{array}$ & $\begin{array}{l}0.32-0.50 \\
0.28-0.57\end{array}$ & $\begin{array}{l}0 \cdot 21 \\
0 \cdot 24\end{array}$ & $\begin{array}{l}0 \cdot 14-0.29 \\
0 \cdot 14-0.38\end{array}$ & $\begin{array}{l}0.07 \\
0.04\end{array}$ & $\begin{array}{l}0.03-0.13 \\
0.01-0 \cdot 15\end{array}$ \\
\hline
\end{tabular}

B

\begin{tabular}{|c|c|c|c|c|c|c|c|c|c|c|c|c|c|c|}
\hline \multirow[b]{2}{*}{$\begin{array}{l}\text { NFI } \\
\text { severity }\end{array}$} & \multirow[b]{2}{*}{$\begin{array}{c}\text { Nerve } \\
\text { modality }\end{array}$} & \multicolumn{5}{|c|}{ Outcome at 12 months } & \multicolumn{8}{|c|}{ Outcome at 12 months } \\
\hline & & Full & Partial & Same & Worse & Total & Full & $95 \% C I$ & Partial & $95 \% C I$ & Same & $95 \% C I$ & Worse & $95 \% C I$ \\
\hline \multirow[t]{2}{*}{ Mild $^{\mathrm{a}}$} & All sensory & 19 & 6 & 6 & 9 & 40 & 0.48 & $0 \cdot 32-0 \cdot 64$ & $0 \cdot 15$ & $0 \cdot 06-0 \cdot 31$ & $0 \cdot 15$ & $0 \cdot 06-0.31$ & $0 \cdot 23$ & $0 \cdot 11-0 \cdot 39$ \\
\hline & All motor & 13 & 9 & 4 & 6 & 32 & 0.41 & $0 \cdot 24-0.59$ & $0 \cdot 28$ & $0 \cdot 14-0.47$ & $0 \cdot 13$ & $0 \cdot 04-0 \cdot 30$ & $0 \cdot 19$ & $0.08-0.37$ \\
\hline \multirow[t]{2}{*}{ Severe $^{\mathrm{b}}$} & All sensory & 43 & 45 & 25 & 13 & 126 & $0 \cdot 34$ & $0 \cdot 26-0.43$ & $0 \cdot 36$ & $0.28-0.45$ & $0 \cdot 20$ & $0 \cdot 13-0.28$ & $0 \cdot 10$ & $0 \cdot 06-0 \cdot 17$ \\
\hline & All motor & 14 & 20 & 14 & 3 & 51 & $0 \cdot 27$ & $0 \cdot 16-0 \cdot 42$ & $0 \cdot 39$ & $0 \cdot 26-0.54$ & $0 \cdot 27$ & $0 \cdot 15-0.42$ & $0 \cdot 06$ & $0.02-0.17$ \\
\hline
\end{tabular}

${ }^{\text {a }}$ Mild NFI = patient with no nerve having severe NFI as defined above.

${ }^{\mathrm{b}}$ Severe NFI = presence of any of the following: MRC grades 0,1 for any motor nerve tested; or $3+$ sensory point reduction for ulnar/median nerve distribution; or $5+$ sensory point reduction for posterior tibial nerve distribution. 
Table 4. Outcome of treatment of NFI by duration of NFI symptoms at 4 (A) and 12 (B) months

A

\begin{tabular}{|c|c|c|c|c|c|c|c|c|c|c|c|c|c|c|}
\hline \multirow{2}{*}{$\begin{array}{l}\text { Duration } \\
\text { of NFI }\end{array}$} & \multirow{2}{*}{$\begin{array}{l}\text { Nerve } \\
\text { modality }\end{array}$} & \multicolumn{5}{|c|}{ Outcome at 4 months } & \multicolumn{8}{|c|}{ Outcome at 4 months — proportions } \\
\hline & & Full & Partial & Same & Worse & Total & Full & $95 \% C I$ & Partial & $95 \% C I$ & Same & $95 \% C I$ & Worse & $95 \% C I$ \\
\hline \multirow[t]{2}{*}{$0-1$ month } & All sensory & 28 & 37 & 7 & 10 & 82 & $0 \cdot 34$ & $0 \cdot 24-0.46$ & 0.45 & $0 \cdot 34-0.56$ & 0.09 & $0.04-0.17$ & $0 \cdot 12$ & $0 \cdot 06-0 \cdot 22$ \\
\hline & All motor & 15 & 22 & 5 & 3 & 45 & 0.33 & $0 \cdot 20-0.49$ & 0.49 & $0 \cdot 34-0.64$ & $0 \cdot 11$ & $0.04-0.25$ & 0.07 & $0.02-0.19$ \\
\hline \multirow[t]{2}{*}{$2-6$ months } & All sensory & 29 & 22 & 24 & 2 & 77 & $0 \cdot 38$ & $0 \cdot 27-0.49$ & $0 \cdot 29$ & $0 \cdot 19-0.40$ & $0 \cdot 31$ & $0.21-0.43$ & 0.03 & $0.00-0 \cdot 10$ \\
\hline & All motor & 9 & 15 & 12 & 1 & 37 & $0 \cdot 24$ & $0 \cdot 12-0.42$ & 0.41 & $0.25-0.58$ & $0 \cdot 32$ & $0 \cdot 09-0 \cdot 26$ & 0.03 & $0.00-0.16$ \\
\hline \multicolumn{15}{|l|}{ B } \\
\hline & & \multicolumn{5}{|c|}{ Outcome at 12 months } & \multicolumn{8}{|c|}{ Outcome at 12 months - proportions } \\
\hline $\begin{array}{l}\text { Duration } \\
\text { of NFI }\end{array}$ & $\begin{array}{c}\text { Nerve } \\
\text { modality }\end{array}$ & Full & Partial & Same & Worse & Total & Full & $95 \% C I$ & Partial & $95 \%$ CI & Same & $95 \%$ CI & Worse & $95 \% C I$ \\
\hline \multirow[t]{2}{*}{$0-1$ month } & All sensory & 29 & 30 & 12 & 18 & 89 & 0.33 & $0.23-0.43$ & $0 \cdot 34$ & $0 \cdot 24-0.45$ & $0 \cdot 13$ & $0.07-0 \cdot 23$ & $0 \cdot 20$ & $0 \cdot 13-0.30$ \\
\hline & All motor & 18 & 15 & 8 & 5 & 46 & $0 \cdot 39$ & $0 \cdot 25-0.55$ & $0 \cdot 33$ & $0.20-0.48$ & $0 \cdot 17$ & $0.08-0 \cdot 32$ & $0 \cdot 11$ & $0.04-0.24$ \\
\hline \multirow[t]{2}{*}{$2-6$ months } & All sensory & 33 & 21 & 19 & 4 & 77 & 0.43 & $0.32-0.55$ & 0.27 & $0 \cdot 18-0 \cdot 39$ & $0 \cdot 25$ & $0 \cdot 16-0 \cdot 36$ & 0.05 & $0.02-0.13$ \\
\hline & All motor & 9 & 14 & 10 & 4 & 37 & $0 \cdot 24$ & $0 \cdot 12-0.42$ & $0 \cdot 38$ & $0.23-0.55$ & $0 \cdot 27$ & $0 \cdot 14-0.44$ & $0 \cdot 11$ & $0 \cdot 04-0.26$ \\
\hline
\end{tabular}


that $61 \%$ of patients with sensory loss and $49 \%$ of patients with motor loss showed some recovery. ${ }^{5}$ This study also showed how the improvement is sustained at a year's follow-up, as it was in the present study. Kiran and others found that $74 \%$ of nerves showed 'marked improvement'. ${ }^{2}$ In their review article, Rose and Waters reported that $75 \%$ of patients with loss of nerve function showed some, or a good recovery. ${ }^{15}$ At the same project, BecxBleumink and Berhe reported that $88 \%$ of patients with acute nerve function loss regained complete or partial recovery of nerve function. ${ }^{3}$ However, Lockwood and others found that only $50 \%$ of patients with neuritis in Hyderabad had some neurological improvement. ${ }^{16}$ In Indonesia, Bernink and Voskens found that $75-80 \%$ of impaired nerves recovered partially or fully, using a standard prednisolone course of a minimum of 10 weeks. ${ }^{17}$ Van Brakel found that nerve function improved in $30-84 \%$ of 186 patients (depending on the type of nerve). Schreuder in Thailand found that $83 \%$ of patients without impairments at the start of MDT and who developed NFI during treatment improved partially or completely with prednisolone. ${ }^{18}$ Sugumaran in India found that $67 \%$ of paralysed ulnar nerves, $86 \%$ of median nerve paralyses and $78 \%$ of foot drops had partial or full recovery. His patients had more severe impairment of function than those in other studies, and he used long courses of corticosteroids (8-10 months). ${ }^{19}$ A recent study in China using a standardized outpatient regimen reported that sensory NFI responded well with a recovery rate of $73.8,76.5$ and $81.0 \%$ in the ulnar, median and posterior tibial nerves, respectively. Recovery of motor function was much less satisfactory. ${ }^{6}$

The present study did not find convincing differences in the responses of different nerves, although there is a suggestion that for sensory function, the ulnar nerve responds best (77\% improved at 12 months, versus $64 \%$ improvement for posterior tibial and $71 \%$ for median); and that for motor function the facial nerve recovers best ( $84 \%$ at 12 months), and the lateral popliteal recovers least well (47\% improved at 12 months, versus $68 \%$ ulnar and $70 \%$ median). However, the $95 \%$ CIs (not given) are very wide. Other studies have reported different findings. Several studies report that median nerve sensory and motor function respond more readily than does ulnar..$^{2,3,6,19-21}$ The facial nerve is also reported as responding well with $70-75 \%$ of nerves recovering in two studies. ${ }^{3,22}$ However, Van Brakel reported a much reduced recovery rate of $30 \%$. Jiang reports good recovery of the posterior tibial nerve. ${ }^{6}$ Taken together, the picture is variable and it may be summarized as broadly showing that there is an overall level of improvement of approximately $60-80 \%$ in impaired nerves following corticosteroid therapy.

The untreated group showed some rather surprising levels of recovery. By 12 months, $33 \%(19-51)$ of the function of untreated motor nerves had improved, with $9 \%(2-25)$ showing full recovery at 12 months [versus 33\% (23-44) with full recovery amongst the treated group]. This proportion had risen from $20 \%$ (8-39) at 4 months. Spontaneous sensory recovery appears to be quite considerable, with $62 \%$ (50-73) showing some improvement at 12 months, and $17 \%(10-29)$ showing full recovery [versus $37 \%$ (30-45) with full recovery amongst the treated group]. The lower level of full recovery amongst the untreated group may reflect to some extent the greater severity of impairment - farther from which they had to recover.

Despite the selection bias in the untreated group and the obvious bias towards severity and short duration of symptoms, there is clearly a considerable spontaneous level of recovery, against which background the effectiveness of prednisolone must be set. It is unfortunate that the day has long passed when it would be ethical to conduct a randomized controlled trial to establish the true effectiveness of corticosteroids in the treatment of NFI. 
The BANDS database was set up to record the duration of the most recent NFI present at registration only without recording the length of time more chronic, 'background' NFI was present. During analysis, it became clear that this was something of a design fault, since it has not been possible to determine how many patients had NFI present before the 'treatment episode' that this paper has studied. This has the effect of diluting some of the improvements noted, since chronic impairment may be expected to recover less than more acute NFI.

\section{SEVERITY OF IMPAIRMENT AS AN OUTCOME INDICATOR}

Two studies have reported that the level of impairment at the start of therapy has a bearing on the outcome. Van Brakel found that only $35 \%$ of patients with complete sensory NFI and $11 \%$ with motor paralysis improved to good function, compared with $67 \%$ and $55 \%$ respectively for patients with moderate impairment. ${ }^{8}$ Srinivasan made a similar finding. ${ }^{21}$ The present study, however, found little to substantiate this. A slightly higher proportion of sensory nerves from the severely affected group recovered than from the mildly affected group [70\% (61-78) versus 63\% (46-77)], although this was not statistically significant. Amongst motor nerves there was little difference, 69\% (50-83) of the mildly impaired nerves showed some improvement, compared with 67\% (52-79) amongst the more severely affected nerves. For both sensory and motor nerves, a higher proportion showed full recovery amongst the mildly affected group, although again this did not reach significance at the 5\% level.

Whilst not all of the findings of other authors could not be corroborated from this study, the current study does show that it is possible for some nerves with more severe impairment to recover to full function.

\section{DURATION OF IMPAIRMENT AS AN OUTCOME INDICATOR}

It is generally thought that the more acute the NFI, the better the response to treatment. ${ }^{15}$ Jiang's study shows that patients with sensory NFI with a duration of less than 1 month respond better than patients whose sensory NFI is of longer duration. ${ }^{6}$ However, as in the case of severity of impairment as an indicator, this finding could not be substantiated, with relatively little difference in outcome at 12 months between the two groups, one with NFI duration of $0-1$ month and the other of 2-6 months.

\section{EHF IMPAIRMENT SCORES}

The EHF impairment score of $0-12$ has been used to give a more accurate picture of impairment than the standard WHO 0-2 disability grading system amongst leprosy patients, by assigning a WHO disability grade to each limb and eye, and summing the results for a total score. This method is rather different from the method already used. There is evidence that the EHF score does provide a fair indication of the impairment experienced by an individual. ${ }^{23}$ In this respect, the changes detected in mean and median EHF scores probably represent a more realistic improvement for the patient himself. Motor NFI will register in the EHF scoring system only if there is a visible deformity (i.e. MRC grade $\leq 2$ or lagophthalmos); whilst a WHO score of 1 for sensory NFI in a limb may indicate a small patch of anaesthesia or a loss of sensation in the entire limb. Further, it gives a level of impairment for a patient; the other method used in this study refers to nerves. However, it may be expected to at least parallel the findings discussed so far. In this respect, it gives 
a clear indication that prednisolone treatment is effective, since there is a statistically significant $(P<0.001)$ improvement in average EHF score from $2.02 \pm 0.21$ at the start of therapy to $1.19 \pm 0.21$ at 4 months, rising slightly to $1.33 \pm 0.27$ at 12 months, an overall improvement of $34 \%$. The median score similarly improved from 2 to 1 , confirming this finding. The average EHF score amongst the untreated patients at the start of treatment was $2 \cdot 32 \pm 0 \cdot 22$, confirming the earlier finding that the nerves in the untreated group were more severely impaired, and thus underlining the heterogeneity of the two groups. However, the mean EHF score for this group, whilst recovering, improved much less than in the treated group (to $2 \cdot 13 \pm 0.25$ at 12 months), and the change was not significant at the $5 \%$ level. In addition, the median score did not change from 2 .

\section{UNTREATED GROUP}

The discovery of a group of patients with acute NFI who should have received prednisolone therapy but did not is a significant finding in its own right. In all, $34 \%$ of the total number of patients needing prednisolone treatment for NFI did not receive it. This proportion of patients is an important indicator of a programme's effectiveness in the prevention of disability, and reasons for a high proportion of 'unjustly untreated' patients should be considered carefully.

The untreated group matched the treated group well in this study for sex, age and leprosy group. However there were distinct differences in terms of duration and severity of NFI, with a statistically significant bias towards more severe and acute impairment in the untreated group. This was perhaps the opposite of what was expected, that is, that mildly impaired patients with longstanding NFI would be missed. However, since the severity score is an absolute, and not a relative measure, this means that patients with longstanding NFI present before an acute episode and who then develop an acute episode, i.e. deteriorate further, will fall into the 'severe' category. Some of the missed patients therefore developed new NFI against a background of chronic impairment and this may explain in part why they were overlooked. Another important finding in this group was that many of them had a gradual decline in NFI over several months, rather than a sudden step-down in NF scoring. The field staff tended to look back to the records of the last month or two in assessing deterioration and thus missed NF loss spread out over several months. In addition, recovery followed by new, significant loss seemed to catch staff out.

The finding of spontaneous recovery amongst the 'unjustly untreated' group should be carefully interpreted. The levels of full recovery were much lower than among the treated group, and it is this which parallels the insignificant change in mean and median EHF scores which occurred amongst the untreated group of patients, since it takes full recovery for a patient to shift his WHO disability grade for a particular limb or eye. It is perhaps best to conclude that while there is evidence of spontaneous recovery, for most patients this may not amount to much.

Further examination of the 'unjustly untreated' group revealed that the clinical picture of leprosy and NFI was complicated by other disease entities (e.g. stroke) in nine cases. The clinical judgement of the field staff not to treat these patients according to the guidelines is respected, and may not necessarily have been incorrect.

\section{LIMITATIONS OF PREDNISOLONE THERAPY}

Despite prednisolone's effectiveness in treating acute NFI, there remains a core of patients who are resistant to its effects. As an overall figure, 32\% (26-38) of all impaired nerves 
were the same or worse at 12 months, despite prednisolone therapy; in 12\% (9-17) nerve function had deteriorated. All these cases were treated with prednisolone in adequate doses within 6 months, the generally accepted treatment period for prednisolone treatment. Prednisolone has its limitations, and the authors agree with Van Brakel that it is important to search actively for more effective treatment for NFI. ${ }^{8}$ Currently, ILEP is funding pilot studies on the use of azathioprine and cyclosporin in the treatment of type 1 reactions.

\section{Acknowledgements}

We are indebted to the staff of DBLM for participating in this study. Dr Rosemary Croft made many helpful suggestions for which we thank her. We are grateful to Mrs Jane Denny for reading and correcting the manuscript. BANDS is funded by The Leprosy Mission International.

\section{References}

${ }^{1}$ Britton WJ. The management of leprosy reversal reactions. Lepr Rev, 1998; 69: 225-234.

2 Kiran KU, Stanley JN, Pearson JM. The outpatient treatment of nerve damage in patients with borderline leprosy using a semi-standardized steroid regimen. Lepr Rev, 1985; 56: 127-134.

3 Becx-Bleumink M, Berhe D. Occurrence of reactions, their diagnosis and management in leprosy patients treated with multidrug therapy; experience in the leprosy control program of the All Africa Leprosy and Rehabilitation Training Center (ALERT) in Ethiopia. Int J Lepr, 1992; 60: 173-184.

${ }^{4}$ De Rijk AJ, Gabre S, Byass P, Berhanu T. Field evaluation of WHO-MDT of fixed duration, at ALERT, Ethiopia: the AMFES project-II. Reaction and neuritis during and after MDT in PB and MB leprosy patients. Lepr Rev, 1994; 65: 320-332.

5 Croft RP, Richardus JH, Smith WC. Field treatment of acute nerve function impairment in leprosy using a standardized corticosteroid regimen-first year's experience with 100 patients. Lepr Rev, 1997; 68: 316-325.

6 Jiang J, Watson JM, Zhang GC, Wei XY. A field trial of detection and treatment of nerve function impairment in leprosy-report from national POD pilot project. Lepr Rev, 1998; 69: 367-375.

7 Becx-Bleumink M, Berhe D, Mannetje W. The management of nerve damage in the leprosy control services. Lepr Rev, 1990; 61: 1-11.

${ }^{8}$ Van Brakel WH, Khawas IB. Nerve function impairment in leprosy: an epidemiological and clinical study-part 2: results of steroid treatment. Lepr Rev, 1996; 67: 104-118.

9 Anonymous. WHO Expert Committee on Leprosy, 7th report. World Health Organization Technical Report Series, 1998; 874: 1-43.

10 Croft RP, Richardus JH, Nicholls PG, Smith WCS. Nerve function impairment in leprosy: design, methodology and intake status of a prospective cohort study of 2664 new leprosy cases in Bangladesh (the Bangladesh Acute Nerve Damage Study). Lepr Rev, 1999; 70: 140-159.

11 Anonymous. A guide to leprosy control. WHO, Geneva, 1988.

12 De Rijk AJ, Gabre S, Byass P, Berhanu T. Field evaluation of WHO-MDT of fixed duration at ALERT, Ethiopia: the AMFES project-I. MDT course completion, case-holding and another score for disability grading. Lepr Rev, 1994; 65: 305-319.

13 Reed NK, van Brakel WH, Reed DS. Progress of impairment scores following commencement of chemotherapy in multibacillary leprosy patients. Int J Lepr, 1997; 65: 328-336.

14 Saunderson P, Currie H, Byass P, Van Brakel W. The EHF score: what is it? Int J Lepr, 1998; 66: 74A.

15 Rose P, Waters MF. Reversal reactions in leprosy and their management [editorial]. Lepr Rev, 1991; 62: 113-121.

16 Lockwood DN, Vinayakumar S, Stanley JN, McAdam KP, Colston MJ. Clinical features and outcome of reversal (type 1) reactions in Hyderabad, India. Int J Lepr, 1993; 61: 8-15.

17 Bernink EH, Voskens JE. Study on the detection of leprosy reactions and the effect of prednisolone on various nerves, Indonesia. Lepr Rev, 1997; 68: 225-232.

18 Schreuder PA. The occurrence of reactions and impairments in leprosy: experience in the leprosy control program of three provinces in northeastern Thailand, 1978-1995. III. Neural and other impairments. Int J Lepr, 1998; 66: $170-181$.

19 Sugumaran DS. Steroid therapy for paralytic deformities in leprosy. Int J Lepr, 1997; 65: 337-344. 
20 Touw-Langendijk EM, Brandsma JW, Andersen JG. Treatment of ulnar and median nerve function loss in borderline leprosy. Lepr Rev, 1984; 55: 41-46.

${ }^{21}$ Srinivasan H, Rao KS, Shanmugam N. Steroid therapy in recent 'quiet nerve paralysis' in leprosy. Report of a study of twenty-five patients. Lepr Ind, 1982; 54: 412-419.

${ }^{22}$ Kiran KU, Hogeweg M, Suneetha S. Treatment of recent facial nerve damage with lagophthalmos, using a semistandardized steroid regimen. Lepr Rev, 1991; 62: 150-154.

23 Saunderson P, Amenu A, Abebe G. Assessment of disability due to leprosy in relation to EHF score. Int J Lepr, 1998; 66: 73A. 